Please do not remove this page

RMIT

UNIVERSITY

\title{
Influence of nano-graphite platelet concentration on onset of crystalline degradation in polylactide composites
}

Narimissa, Esmaeil; Gupta, Rahul; Bhaskaran, Madhu; Sriram, Sharath

https://researchrepository.rmit.edu.au/esploro/outputs/9921858366401341/filesAndLinks?institution=61RMIT_INST\&index=null

Narimissa, E., Gupta, R., Bhaskaran, M., \& Sriram, S. (2012). Influence of nano-graphite platelet concentration on onset of crystalline degradation in polylactide composites. Polymer Degradation and Stability, 97(5), 829-832. https://doi.org/10.1016/j.polymdegradstab.2012.02.010

Document Version: Accepted Manuscript

Published Version: https://doi.org/10.1016/j.polymdegradstab.2012.02.010

Repository homepage: https://researchrepository.rmit.edu.au

(C) 2012 Elsevier Ltd.

Downloaded On 2023/04/26 23:57:41 +1000

Please do not remove this page 
Thank you for downloading this document from the RMIT Research Repository.

The RMIT Research Repository is an open access database showcasing the research outputs of RMIT University researchers.

RMIT Research Repository: http://researchbank.rmit.edu.au/

\section{Citation:}

Narimissa, E, Gupta, R, Bhaskaran, M and Sriram, S 2012, 'Influence of nano-graphite platelet concentration on onset of crystalline degradation in polylactide composites', Polymer Degradation and Stability, vol. 97, no. 5, pp. 829-832.

See this record in the RMIT Research Repository at:

http://researchbank.rmit.edu.au/view/rmit:15413

Version: Accepted Manuscript

Copyright Statement: (c) 2012 Elsevier Ltd.

Link to Published Version:

http://dx.doi.org/10.1016/j.polymdegradstab.2012.02.010 


\title{
Influence of nano-graphite platelet concentration on onset of crystalline degradation in polylactide composites
}

\author{
Esmaeil Narimissa, ${ }^{a}$ Rahul Gupta, ${ }^{a}$ Madhu Bhaskaran, ${ }^{b}$ and Sharath Sriram, ${ }^{* b}$ \\ ${ }^{a}$ Rheology and Materials Processing Centre, RMIT University, GPO Box 2476, Melbourne, \\ Victoria 3001, Australia. \\ ${ }^{b}$ Functional Materials and Microsystems Research Group, RMIT University, GPO Box 2476, \\ Melbourne, Victoria 3001, Australia. \\ *E-mail: sharath.sriram@gmail.com; Tel.: +61-3-99250440; Fax: +61-3-99253242
}

\begin{abstract}
Nano-carbon fillers offer enhanced thermal and mechanical properties to biodegradable polymer matrices. In this work, we study extruded nano-graphite platelet (NGP) loaded polylactide (PLA) using thermal, mechanical, and microstructural analysis techniques. The influence of NGP-loading on polymer crystallization, the Young's modulus, tensile strength, and crystallography of the polymer composite are determined. We establish the optimal NGP loading concentration beyond which agglomeration effects degrade crystalline and structural properties of PLA-NGP composites.
\end{abstract}

Keywords: polylactide, PLA, nano-graphite platelet, NGP, mechanical properties, loading concentration, crystallisation 


\section{INTRODUCTION}

Polymer-based composites began in the 1960s as a new concept for advanced materials. By dispersing strong and stiff fibres within polymer matrices, composite materials offering significant structural benefits with respect to weight loss reduction, durability, and mechanical performance were developed. The enhanced performance of polymer composites is a result of interfacial bond chemistry as well as the degree of nano-additive dispersion and the resultant morphology.

Early in 1990s, an important discovery which promised to revolutionize the field of nano-material science was made in the form of carbon-based nano-fillers. Addition of minute quantities of carbon nano-tubes (CNTs) or carbon nano-fibres (CNFs) to polymer resins promised polymer nano-composites with enhanced thermal, mechanical, and electrical performance. Significant advantages from nano-carbon dispersion were determined when dispersed in the polymer matrix. However, when dispersed in the polymer matrix through viable mixing techniques (e.g., melt blending and solvent casting), these carbon-based nano-fillers are likely to exhibit strong van der Waals' interaction. This results in agglomeration, and therefore, inhomogeneous composites [1-3].

Recently, a new breed of cost-effective carbon based nano-dimensional materials named as nano-graphite platelets (NGP) has emerged. They promise to eliminate the problems associated with nano-clays, CNTs, or CNFs while offering potentially enhanced performance as well as being a low cost alternative [4-6]. The potential 
applications of graphene-polymer composites include single molecule gas detection, transparent conducting electrodes, and energy storage devices such as supercapacitors and lithium ion batteries [7]. Moreover, the highest thermal conductivity reported in literature so far belongs to nano-graphene materials (six times higher than copper). In terms of electrical and mechanical properties they are similar to copper and fifty times stronger than steel while having one fourth density of copper [5,6,8]. This work explores the influence of such nano-graphitic fillers in composites, and the degree of property enhancement and degradation as a function of loading.

Polylactide (PLA) is a thermoplastic biodegradable polyester. This polymer is currently receiving considerable attention for conventional uses, due to its valuable qualities such as biodegradability, production from renewable resources and its numerous functions including packaging materials, production of fibres and composites for technical applications $[9,10]$.

PLA is a rigid thermoplastic biodegradable polymer that can be semi-crystalline, crystalline, or totally amorphous, depending on the stereo purity of the polymer backbone. PLA is a unique polymer that in many ways behaves like polyethylene terephthalate, but also performs a lot like polypropylene; a polyolefin. Ultimately, it can potentially be utilised in the broadest range of applications because of its ability to be stress crystallised, thermally crystallised, impact modified, filled, copolymerised, and processed in most polymer processing equipment [11]. Nevertheless, the application of PLA in engineering devices such as solar panels and in mechanical and automotive parts requires enhancements in its properties via combining this polyester matrix with 
different dispersed phases such as nanofillers, plasticisers, impact modifiers, and flameretardants $[12,13]$.

\section{MATERIALS AND METHODS}

For this study, PLA composites with NGP fillers were prepared via melt intercalation mixing process. The NGP loading (or doping) concentration was determined based on the weight percentage of the starting mixture. NGPs and PLA pellets were dry mixed in different compositions ( $0-10 \mathrm{wt} \% \mathrm{NGP})$ prior to melt intercalation process. This was followed by melt blending in a Brabender Twin Screw extruder at $180{ }^{\circ} \mathrm{C}$ and $40 \mathrm{rpm}$ mixing condition. Finally, the melt blended pellets underwent compression moulding process, at $180{ }^{\circ} \mathrm{C}$ and $80 \mathrm{kN}$ pressure for $5 \mathrm{~min}$, to form dog bone-shaped ASTM D638 specimens.

Thermal characterisation of the nanocomposites was performed by modulated differential scanning calorimetry (MDSC) utilising a TA Instrument Model 2920 under nitrogen flow. The heating scan was carried out at $2{ }^{\circ} \mathrm{C} \min ^{-1}$ modulated at $\pm 0.5{ }^{\circ} \mathrm{C}$ in $40 \mathrm{~s}$. The mechanical properties of the pure PLA and NGP-loaded PLA composites were determined through tensile testing characterization technique (Instron 4467) at speed rate of $1 \mathrm{~mm} \mathrm{~min}^{-1}$ with a distance of $115 \mathrm{~mm}$ between the grips and under ambient conditions.

$\mathrm{X}$-ray diffraction $(\mathrm{XRD})$ was carried out using a Rigaku wide angle $\mathrm{X}$-ray instrument at wavelength of $0.154 \mathrm{~nm}$ in $2 \theta$ range of $10-80^{\circ}$ was utilised. Micro-Raman characterization (Renishaw InVia spectrometer) was performed with $633 \mathrm{~nm}$ 
wavelength at a laser power of $1.7 \mathrm{~mW}$ and with 3 accumulations for $20 \mathrm{~s}$ exposures [14].

\section{RESULTS AND DISCUSSION}

The MDSC analysis was used to determine the glass transition temperature, crystallization characteristics, and melting properties of the NGP-loaded PLA nanocomposites. The results showed no significant change in the glass transition temperature $\left(\mathrm{T}_{\mathrm{g}}\right)$ for the nanocomposites, which was consistently $59-60{ }^{\circ} \mathrm{C}$. Likewise the melting temperature ( $\left.T_{m}\right)$ also did not appear to be influenced by the NGP loading, with values of $149-151^{\circ} \mathrm{C}$ for all samples. However, the crystallisation properties of the nanocomposites were significantly influenced by the NGP concentration. The changes in crystallization temperature $\left(T_{c}\right)$ and percentage crystallinity as a function of NGP concentration are presented in Fig. 1. The maximum percentage of crystallinity is at $1 \mathrm{wt} \%$ of NGP in PLA, before significant reduction. The crystallization temperature also shows a maximum at 1-3 wt $\%$ NGP in PLA before reducing. An increase in $\mathrm{T}_{\mathrm{c}}$ at $10 \mathrm{wt} \%$ of NGP occurs, which could possibly be due to the increased presence of agglomerated NGP potentially contributing carbon's thermal properties to the measurement.

The measured Young's modulus, tensile strength, and elongation at break of the NGP-loaded PLA composite materials are presented in Fig. 2. The Young's modulus (continuous blue line) shows a sharp over two-fold increase for $3 \mathrm{wt} \%$ NGP loading, before a gradual roll-off with increasing loading. The increased modulus as a result of 
NGP loading is a desired characteristic, as the PLA-based composite incorporates the mechanical properties of NGPs. The tensile strength (dashed green line) shows an almost linear decrease, except for an increase for the $1 \mathrm{wt} \%$ NGP loading. The elongation at break data (dotted orange line) also typically decreases with increased NGP loading, displaying a trend very similar to the tensile strength's dependence on NGP concentration.

To understand the role of NGP loading on the thermal and mechanical properties, a microstructural investigation of the pure and NGP-loaded PLA composites was undertaken.

$\mathrm{X}$-ray diffraction (XRD) analysis was carried out to determine the crystallographic properties of the composites. The diffractograms (shown with offsets in Fig. 3) were recorded for the samples at ambient condition and show a scattered intensity distribution with a broad maximum around $2 \theta$ of $\sim 16.5^{\circ}$ suggesting a semi-crystalline structure of PLA. The diffractograms also have a peak at $2 \theta$ of $\sim 26^{\circ}$ corresponding to the (002) graphitic carbon structure. The peak position for the (002) carbon occurs at the same position in all composites, suggesting that the melt-blending process did not separate the graphite layers, with the majority of them still present in aggregate structure. An increasing intensity for this graphitic peak is also apparent. However, the peak corresponding to the semi-crystalline PLA at $\sim 16.5^{\circ}$ varies in intensity with the increased NGP loading.

The normalised intensity for the $\sim 16.5^{\circ}$ PLA peak (continuous brown line) is compared in Fig. 4 with the trend observed for the tensile strength measured (dashed 
green line). With very low $1 \mathrm{wt} \%$ NGP loading, the semi-crystalline PLA intensity is enhanced two-fold (relative intensity of 2.17), before decreasing to a value of 1.77 for both $3 \mathrm{wt} \%$ and $5 \mathrm{wt} \%$ NGP loading followed by a further sharper decrease in crystalline contribution. This result is in agreement with the percentage crystallinity measurements by MDSC presented in Fig. 1 .

Further investigation of the microstructural characteristics of the composites was carried out using micro-Raman spectroscopy. Micro-Raman characterization (Renishaw InVia spectrometer) was performed with $633 \mathrm{~nm}$ wavelength at a laser power of $1.7 \mathrm{~mW}$ and with 3 accumulations for $20 \mathrm{~s}$ exposures [14]. The Raman spectra obtained for PLA with various NGP loading concentrations are shown in Fig. 5(a). The spectrum for pure PLA shows expected peaks at 393, 872, 1041, 1097, 1126, 1295, 1386, 1451, and $1769 \mathrm{~cm}^{-1}$. The peaks at 872 and $1444 \mathrm{~cm}^{-1}$ are the most intense and correspond to the stretch of the carbon-carbonyl bond and bending of the methyl structure, respectively $[15,16]$.

The spectra for NGP-doped PLA show peaks at $\sim 1580 \mathrm{~cm}^{-1}$ which corresponds to the $G$ peak in crystalline graphite [17]. As the doping levels increase, the peak at $1580 \mathrm{~cm}^{-1}$ increases in intensity, while the intensity of the PLA peak at $872 \mathrm{~cm}^{-1}$ rapidly decreases as expected. A broad band at $\sim 1335 \mathrm{~cm}^{-1}$ emerges at higher doping concentrations of NGP, and this corresponds to the $D$ peak related to defected graphite [17].

The intensity ratios of the three peaks of interest are shown as a function of NGP loading in Fig. 5(b). The intensity ratio of 1580 to $872 \mathrm{~cm}^{-1}$ peaks and the 1335 to $872 \mathrm{~cm}^{-1}$ peaks rises linearly until about $5 \mathrm{wt} \%$ NGP loading, and then plateaus with 
increasing concentration. This levelling off indicates that further doping does not significantly impact the chemical structure of the PLA, and can be attributed to NGP agglomeration at higher concentrations [1-3]. The intensity ratio of the 1580 and $1335 \mathrm{~cm}^{-1}$ peaks is indicative of the level and quality of dispersion of nano-fillers in the polymer matrix. A higher intensity ratio is preferred as this shows the dominance of the crystalline layered NGP over agglomerates (related to the peak at $1335 \mathrm{~cm}^{-1}$ ). The ratio of crystalline to defected carbon is highest at $5 \mathrm{wt} \%$ loading of NGP in PLA.

In relating the microstructural characterisation to the thermal and mechanical properties measured (Figs. 1 and 2), the results indicate that a low $1 \mathrm{wt} \%$ NGP loading enhances properties in general. NGP loading of 3-5 wt $\%$ contributes to enhancement in Young's modulus in the PLA-based composites. XRD and micro-Raman spectroscopy indicate that PLA retains a semi-crystalline structure at the 3-5 wt\% loading concentration, with the NGP also existing in a layered graphitic state. Higher levels of NGP loading appear to degrade the PLA composites resulting in loss of crystallinity, apparently driven by the increase in defective carbon possibly from the inclusion of agglomerates and tactoids in the polymer matrix.

\section{CONCLUSIONS}

In summary, we present an investigation of NGP-loaded polylactide polymer composites. The inclusion of nano-graphite platelets is favoured for increased thermal, mechanical, and electrical properties of polymers such as the biodegradable polylactide. We have determined that a 1-5 wt $\%$ loading concentration of NGP can lead to increased 
crystallinity in the polymer matrix and provide improved thermal and mechanical characteristics. Further loading tends to degrade crystalline properties of the polymer matrix, with the inclusion of defective carbon agglomerates and tactoids.

\section{Acknowledgements}

MB and SS acknowledge Australian Research Council (ARC) Post-Doctoral Fellowships through DP1092717 and DP110100262, respectively. Infrastructure support from the ARC through LE100100215 (SS) is also acknowledged. The authors thank Prof. Hyoung J. Choi (Inha University) for support with the XRD measurements.

\section{References}

[1] Ajayan PM, Schandler LS, Giannaris C, Rubio A. Single-walled carbon nanotubepolymer composites: strength and weakness. Adv Mater 2000;12:750-753.

[2] Yang Y, Gupta MC, Dudley K, Lawrence RW. The fabrication and electrical properties of carbon nanofibre-polystyrene composites. Nanotechnol 2004;15:1545-1548.

[3] Coleman JN, Khan U, Blau WJ, Gun'ko YK. Small but strong: A review of the mechanical properties of carbon nanotube-polymer composites. Carbon 2006;44:16241652.

[4] Du XS, Xiao M, Meng YZ, Hay AS. Synthesis and properties of poly(4,4'oxybis(benzene)disulfide/graphite nanocomposites via in-situ ring opening polymerization of macrocyclic oligomers. Polym 2004;45:6713-6718.

[5] Zheng W, Lu XH, Wong SC. Electrical and mechanical properties of expanded graphitereinforced high-density polyethylene. Appl Polym Sci 2004;91:2781-2788.

[6] Ramanathan $\mathrm{T}$ et al. Functionalized graphene sheets for polymer nanocomposites. Nat Nanotechnol 2008;3:327-331. 
[7] Potts JR, Dreyer DR, Bielawski CW, Ruoff RS. Graphene-based polymer nanocomposites. Polym 2011;52:5-25.

[8] Fukushima H, Drzal LT. A carbon nanotube alternative: Graphite nanoplatelets as reinforcements for polymers. Annu Tech Conf Soc Plast Eng 2003;61:2230-2234.

[9] Drumright RE, Gruber PR, Henton DE. Polylactic acid technology. Adv Mater 2000;12:1841-1846.

[10] Dubois P, Murariu M. The "green" challenge: High-performance PLA (nano) composites. JEC Compos Mag 2008;45:66-69.

[11] Henton DE, Gruber P, Lunt J, Randall J. Polylactic acid technology. In: Mohanty AK, Misra M, Drzal LT, editors. Natural fibers, biopolymers, and biocomposites, Boca Raton, FL: Taylor \& Francis, 2005. pp. 527-577.

[12] Bleach NC, Nazhat SN, Tanner KE, Kellomäki M, Törmälä P. Effect of filler content on mechanical and dynamic mechanical properties of particulate biphasic calcium phosphate - polylactide composites. Biomater 2002;23:1579-1585.

[13] Paul MA, Alexandre M, Degée P, Henrist C, Rulmont A, Dubois P. New nanocomposite materials based on plasticized poly(L-lactide) and organo-modified montmorillonites: Thermal and morphological study. Polym 2003;44:443-450.

[14] Bhaskaran M, Sriram S, Adley D, Perova TS, Mitchell A. Reversal and pinning of Curie point transformations in thin film piezoelectrics. CrystEngComm 2011;13:1280-1282.

[15] Kister G, Cassanas G, Vert M. Polym Effects of morphology, conformation and configuration on the IR and Raman spectra of various poly( lactic acid)s. 1998;39:267273.

[16] Smith PB, Leugers A, Kang S, Yang X, Hsu SL. Raman characterization of orientation in poly(lactic acid) films. Macromol Symp 2001;175:81-94.

[17] Ferrari AC et al. Raman spectrum of graphene and graphene layers. Phys Rev Lett 2006;97:187401. 


\section{FIGURE CAPTIONS}

Fig. 1 Thermal properties of pure and NGP-loaded PLA samples as determined by modulated differential scanning calorimetry.

Fig. 2 Mechanical properties of pure and NGP-loaded PLA samples under ambient conditions. Maximum Young's modulus and tensile strength are measured at $3 \mathrm{wt} \%$ and $1 \mathrm{wt} \%$ NGP loading, respectively. The elongation at break data displays a trend identical to the tensile strength.

Fig. 3 X-ray diffraction results for pure and NGP-loaded PLA samples.

Fig. 4 Normalised X-ray intensity of the $16.5^{\circ}$ PLA $2 \theta$ peak (continuous line) compared with the measured tensile strength for pure and NGP-loaded PLA.

Fig. 5 Micro-Raman spectroscopy results for pure and NGP-doped PLA samples are shown in (a). The relative intensity of significant PLA and NGP peaks are compared in (b). 


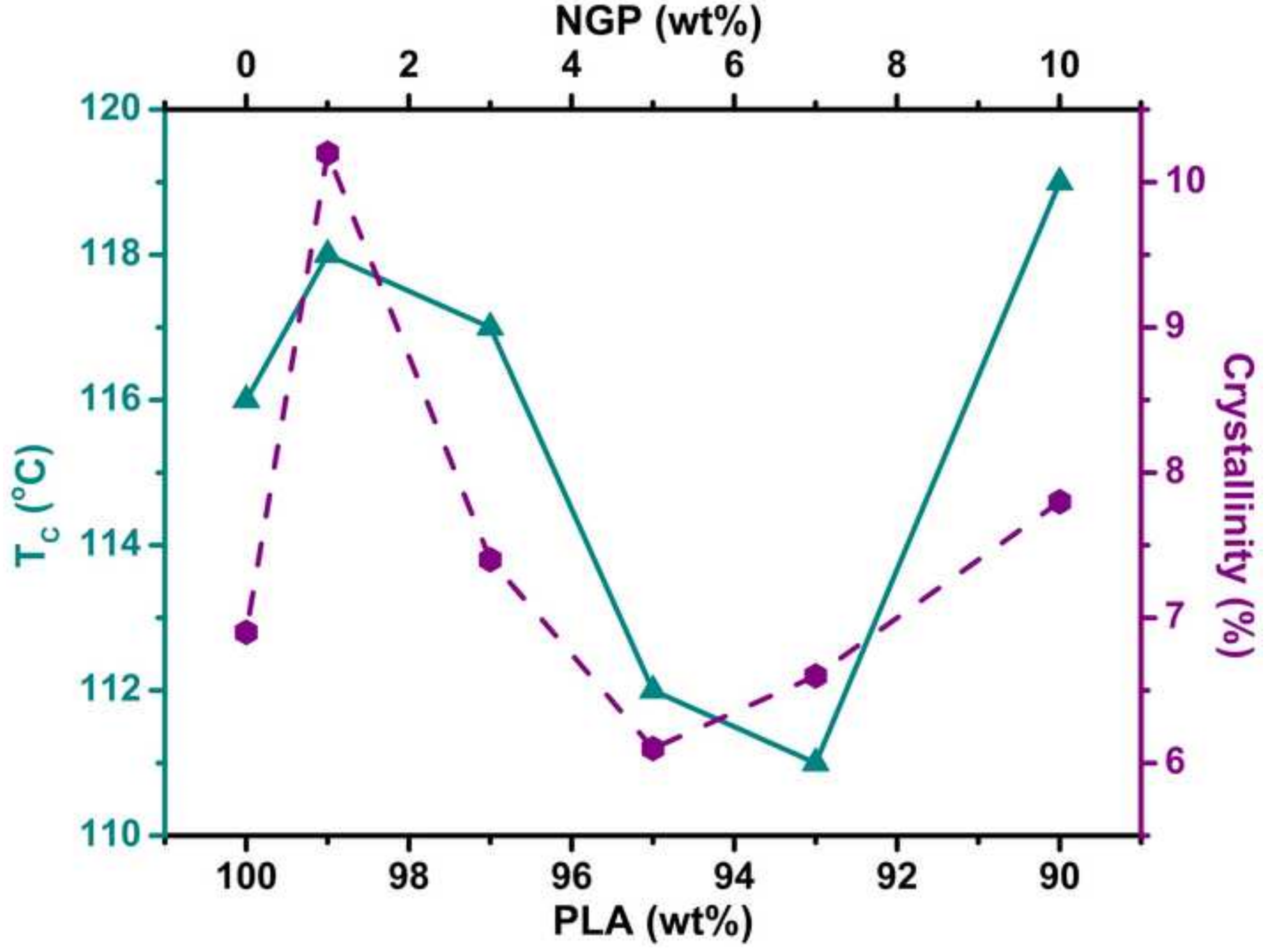




\section{NGP (wt\%)}

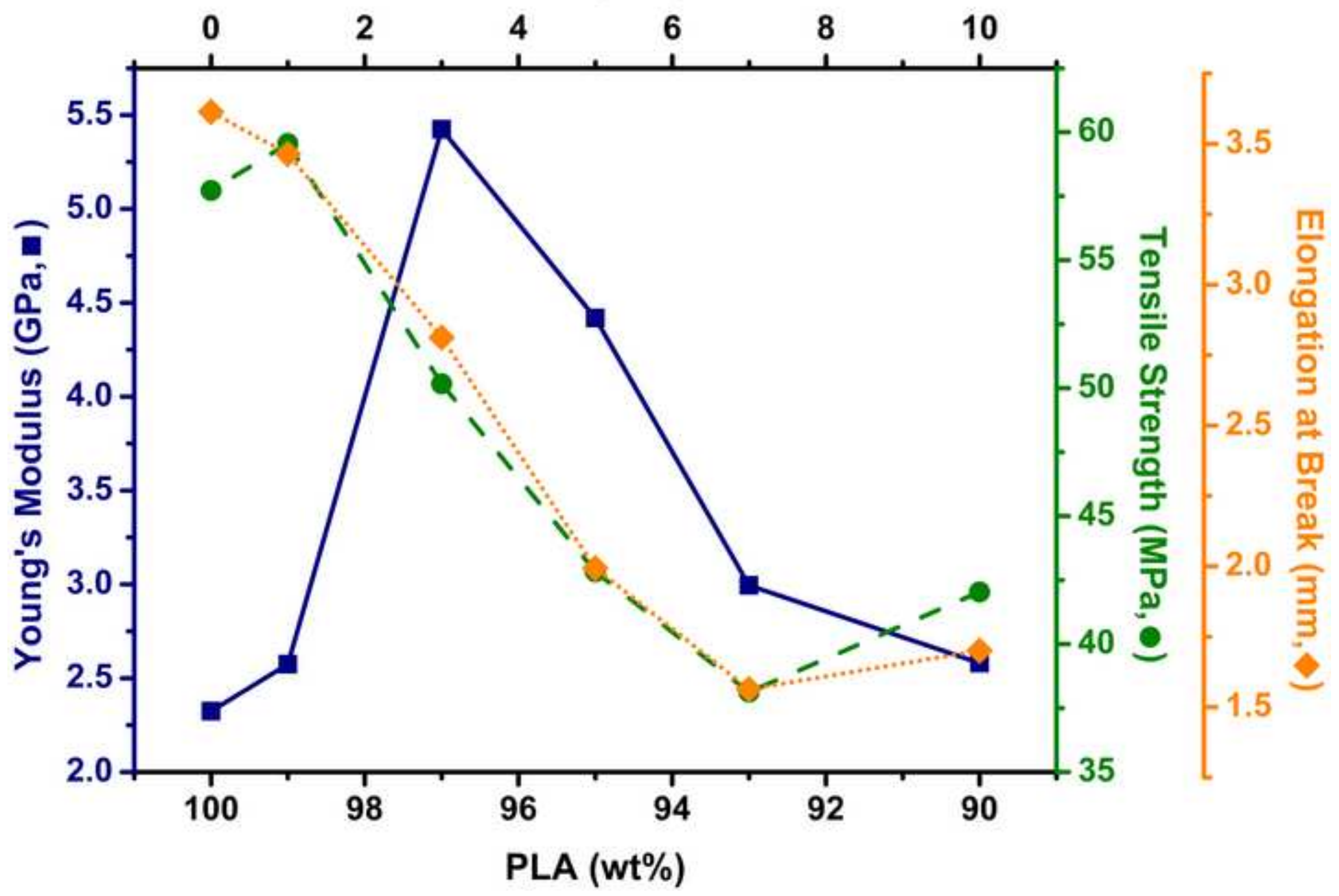


- PLA $100 \mathrm{wt} \%$

— PLA 97 wt\%; NGP 3 wt \%

- PLA 93 wt \%; NGP 7 wt $\%$
— PLA 99 wt\%; NGP 1 wt $\%$

- PLA 95 wt\%; NGP 5 wt \%

- PLA 90 wt \%; NGP 10 wt \%

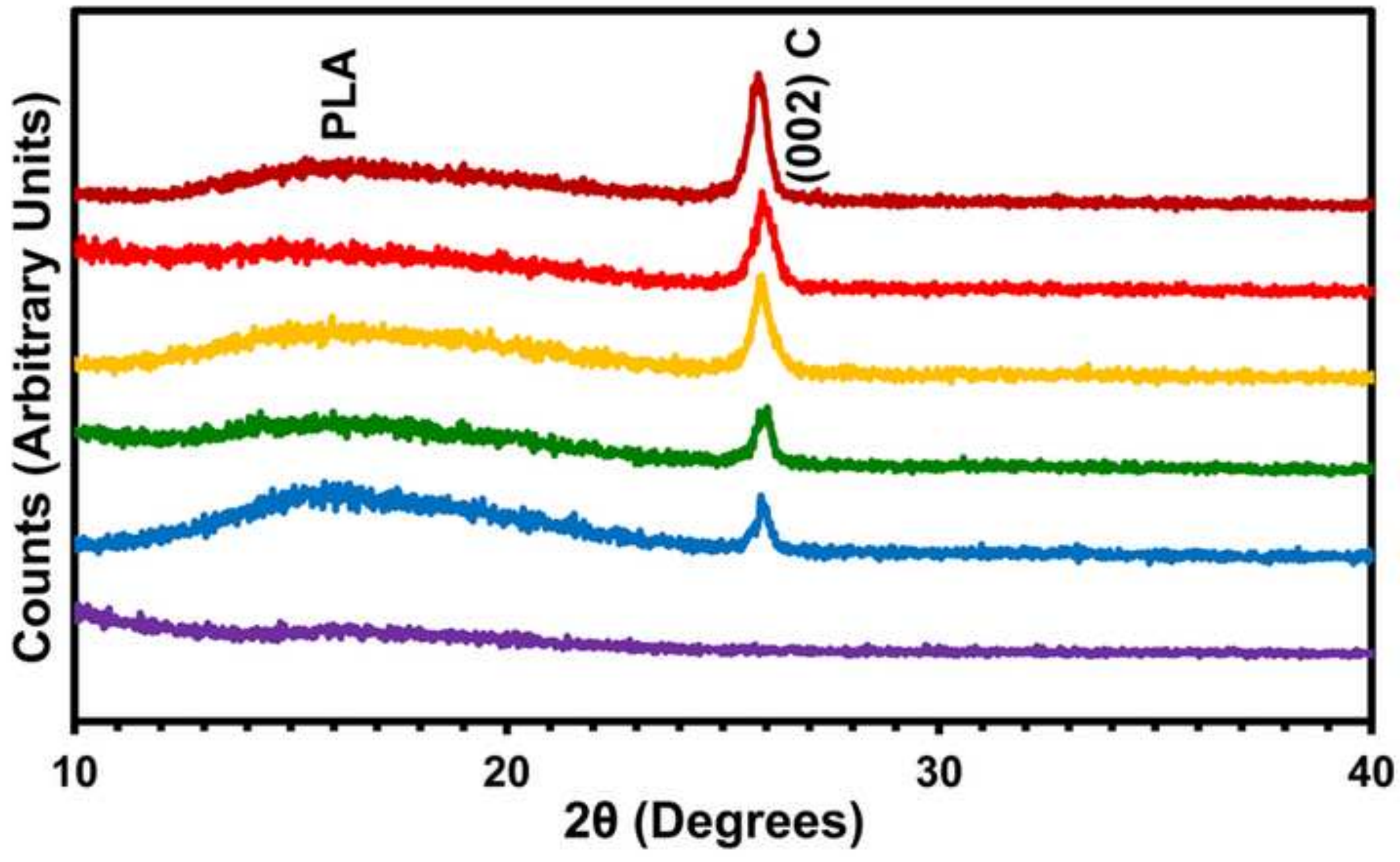




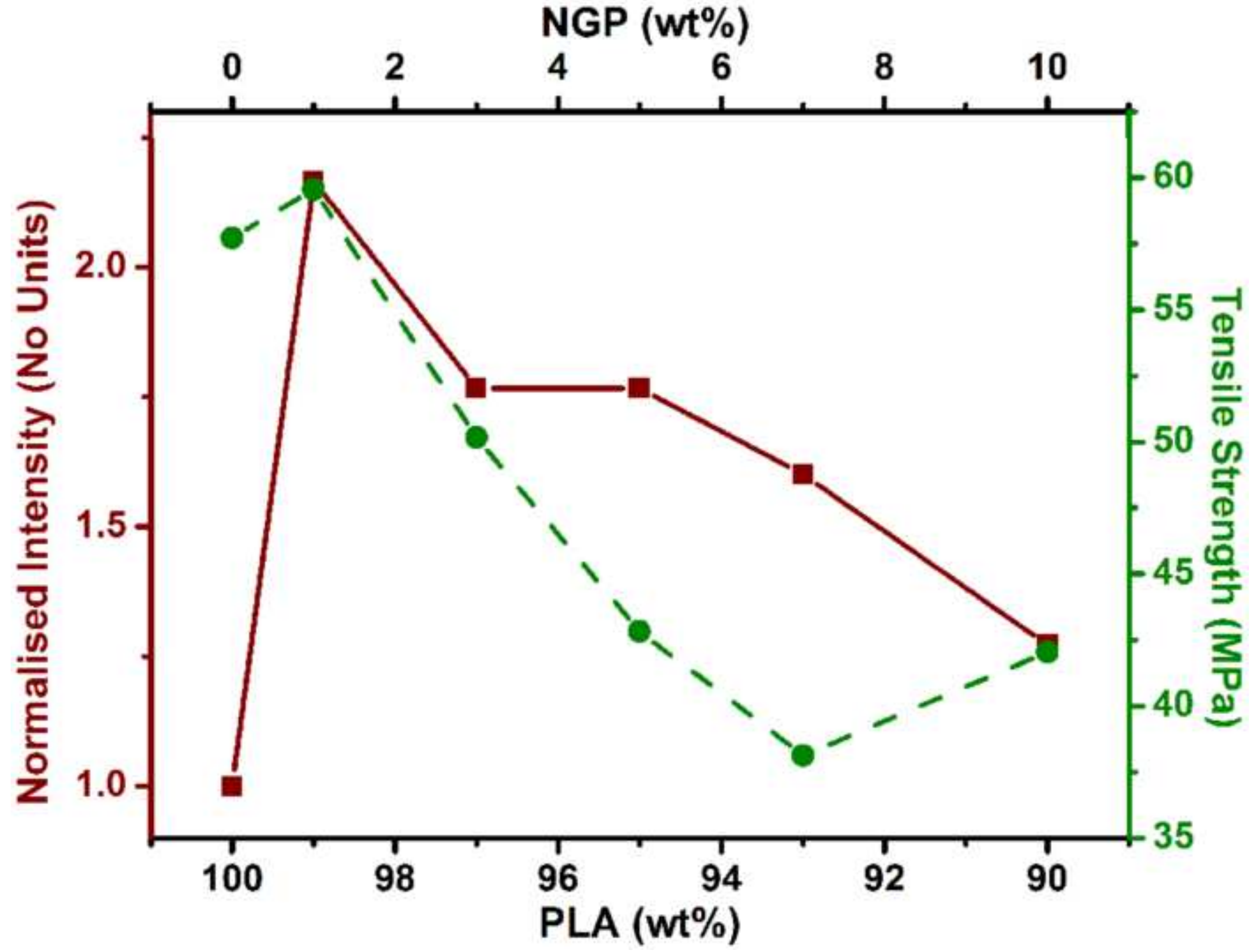


Click here to download high resolution image
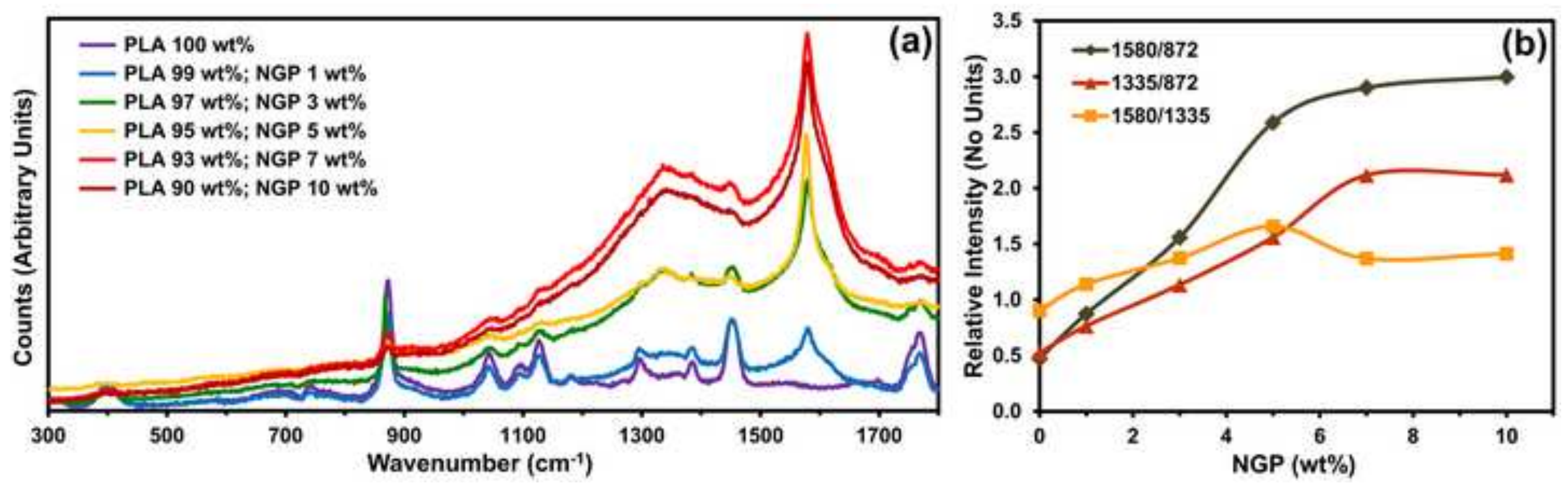